\title{
O ENFERMEIRO NOS NOVOS DISPOSITIVOS ASSISTENCIAIS EM SAÚDE MENTAL
}

\author{
The Nurse in the New Assistance \\ Device in Mental Health \\ El Enfermero en los Nuevos Dispositivos \\ Asistenciales en Salud Mental
}

Claudia Barbastefano Monteiro

\begin{abstract}
Resumo
Trata-se de um relato de experiência que se baseia na prática cotidiana da Enfermagem Psiquiátrica, onde a autora tem por objetivo descrever, em abordagem simples e direta, suas dificuldades de adaptação no cumprimento de seu novo papel como enfermeira de um Hospital-Dia Psiquiátrico, após dez anos de atuação em uma unidade de internação psiquiátrica, e sua atual performance em um centro de atenção diária. Conclui-se que, durante sua formação, o enfermeiro é preparado para incrementar ações técnicas claras e definidas, enquanto o novo modelo proposto pela Reforma psiquiátrica exige deste profissional iniciativa, criatividade e o estabelecimento de vínculos afetivos e sociais.
\end{abstract}

Palavras-chave: Enfermagem Psiquiátrica. Hospital-Dia. Enfermagem em Saúde Comunitária. Hospital Psiquiátrico.

\begin{abstract}
It is about an experience story that is based on the practice of the daily of the Psychiatric Nursing, where the author has for objective to describe in simple and direct boarding, its difficulties of adaptation in the fulfilment of its new paper as nurse of a psychiatric Day Hospital, after ten years of performance in a unit of psychiatric internment, and its current performance in a center of daily attention. It is conclude that during its formation, the nurse is prepared to develop action clear and definite techniques, while the new model considered for the psychiatric Reformation demands of this professional initiative, creativity and the establishment of affective and social bonds.
\end{abstract}

\section{Resumen}

Tratase de un relato de experiencia que se basa en la práctica diaria de la Enfermería Psiquiátrica, donde la autora tiene por objetivo describir en un abordaje simple y directo, sus dificultades de adaptación en el cumplimiento de su nuevo papel como enfermero de un Hospital Día Psiquiátrico, después de diez años de actuación en una unidad de internación psiquiátrica, y de su actual actuación en un centro de atención diaria. Concluyese que durante su formación, el enfermero está preparado para incrementar acciones técnicas claras y definidas, mientras que el nuevo modelo propuesto por la Reforma Psiquiátrica exige de este profesional, iniciativa, creatividad y el establecimiento de enlaces afectivos y sociales.
Keywords: Psychiatric Nursing. Day Hospital. Community Health Nursing. Psychiatric Hospital.
Palabras clave: Enfermería Psiquiátrica. Hospital Día. Enfermería en Salud Comunitaria. Hospital Psiquiátrico. 


\section{INTRODUÇÃO}

A motivação para redigir este texto surgiu das dificuldades de adaptação sentidas por mim, ao desempenhar minha nova função, como enfermeira de um Hospital-Dia Psiquiátrico, após dez anos de atuação na unidade de internação.

Em um período de quatro anos, supervisionei o estágio de nível médio (técnico e auxiliar de enfermagem), em uma unidade de internação psiquiátrica pertencente a uma instituição universitária. Posteriormente, fui convidada a integrar o quadro de enfermeiros desse mesmo hospital como supervisora de enfermagem da Unidade de Internação, cargo que exerci por cinco anos até ser transferida, pela minha chefia, para o Hospital-Dia.

0 hospital-dia seria uma extensão do hospital no meio social, entre os quais existe uma linearidade ligando os dois estabelecimentos. Ele é a intercessão da internação e a sociedade, prestando assistência a uma clientela externa diferenciada tanto da internação como do ambulatório, servindo de modelo substitutivo ao modelo asilar (Jorge ${ }^{1}$ ).

0 serviço de atenção diária busca intermediar a situação de ruptura dos vínculos sociais devido a doenças mentais graves, promovendo novos laços com a família e a comunidade. Esse dispositivo de atenção na comunidade é peça fundamental para a continuidade do cuidado e dele depende 0 avanço do processo de desinstitucionalização (Carvalho²).

Nesses anos em que atuei na Enfermagem Psiquiátrica observei que, no modelo asilar a assistência tende a focalizar a doença do sujeito, seus sinais e sintomas. Entretanto, no novo modelo proposto pela Reforma Psiquiátrica, a assistência está voltada para a reinserção social, o desenvolvimento da autonomia do sujeito, a convivência e a comunicação com o outro, a participação em grupo e 0 desenvolvimento do pragmatismo.

\section{NA INTERNAÇÃO}

Atuava nas enfermarias com uma clientela bastante diversificada, que apresentava distúrbios, tais como: psicoses, depressões, mania, demências, uso de drogas. Procurava conhecer integralmente cada paciente, na esperança que, de minha prática surgissem respostas para minimizar as dúvidas do paciente com transtorno psíquco relacionadas à complexidade do cotidiano da assistência de enfermagem.

Como enfermeira supervisora possuía em minha equipe, três técnicos de enfermagem. Juntos prestávamos cuidados em uma enfermaria com 69 pacientes do sexo feminino, em crise, que demandavam atenção para: higiene, alimentação, administração de medicamentos, aferição de sinais vitais, repouso, cuidados quanto à riscos Também elaborava relatórios de enfermagem, com a descrição do comportamento e ações dos pacientes com base disciplinar e vigilante. Procurava manter sempre uma constante interação visando o relacionamento de ajuda.

A proposta da assistência de enfermagem na internação baseia-se em uma intervenção terapêutica oferecida por meio de dispositivos como o Salão de Beleza, a Oficina de Costura e o Baile realizado aos sábados. Esses dispositivos visam estimular o interesse dos pacientes pelas coisas que os cercam colaborando assim, para a manutenção de seus laços sociais.

Para Loyola e Rocha ${ }^{3}$, o cuidar na Psiquiatria tem sido considerado como um acolher com garantias de: alimentação, higiene, sono, lazer, convívio, privacidade, e outras. E ressaltam que, o cuidar é uma atitude de ocupação, preocupação, responsabilização e envolvimento afetivo com o outro. Logo, ele abrange mais que um momento de atenção e de zelo.

Acredito que a atitude ética do enfermeiro pautada na moral e na deontologia, revela-se de suma importância, ao se prestar um cuidado digno, respeitoso, livre de estigmas, crendices e preconceitos. Centrado na interação, esse cuidado tem por objetivo originar uma relação de ajuda, uma interação terapêutica, que se caracteriza por qualquer contato com a pessoa que precisa de ajuda, para atender a uma demanda.

Para Rodrigues ${ }^{4}$, uma relação de ajuda implica dar parte de seu tempo, sua habilidade, seu conhecimento e interesse e sua capacidade de ouvir e entender 0 que a pessoa expressa e os seus sentimentos.

Porém, um estudo realizado em uma enfermaria psiquiátrica constatou que, o enfermeiro é bastante solicitado para resolver problemas e tomar providências sobre todos as intercorrências que surgem no decorrer do plantão, restando-lhe pouco tempo para prestação de cuidados diretos aos pacientes. Ele assume a demanda relativa ao cargo administrativo, participa de atividades burocráticas, atende a familiares, médicos, profissionais da limpeza, farmácia, cozinha e manutenção, mantém atualizadas provisões e previsões, atividades nas quais a prioridade é considerar a situação mais urgente naquele momento intervindo para solucioná-la, com o objetivo de dar andamento ao serviço. Assim, ele, relega a relação terapêutica a um espaço secundário (Monteiro ${ }^{5}$ ).

A relação terapêutica e as atividades de reabilitação social também ficam prejudicadas devido ao curto espaço de tempo disponível para planejá-las e implementá-las. 


\section{A ADAPTAÇÃO}

Quando fui transferida para o Hospital-Dia sentime insegura e tratei logo de me atualizar quanto à proposta de assistência desse modelo, que é bastante diferente do modelo hospitalocêntrico. Esse modelo, ainda em construção, apóia-se no pensamento de inclusão do usuário em contraposição ao modelo hospitalocêntrico, que lida com as conseqüências da doença e segrega vidas. Mesmo com os novos discursos sobre a ressocialização, pautados na Reforma Psiquiátrica, a mudança na prática cotidiana ainda é lenta, principalmente no modelo asilar, no qual a troca social é praticamente nula.

Segundo Vilas Boas ${ }^{6}$, o modelo asilar exclui o paciente do convívio familiar e social. 0 Hospital-Dia é uma das modalidades assistenciais intermediárias entre a hospitalização e o tratamento no ambulatório, onde 0 paciente recebe tratamento intensivo com enfoque na reabilitação social, para que possa manejar sua doença fora da instituição fechada e objetivar sua reintegração à vida familiar e social, através da compreensão da sua doença e aproximação com a equipe interdisciplinar. 0 paciente busca a construção de um vínculo para a execução de uma tarefa integrada com a proposta de facilitar a evolução das interações pessoais.

Iniciei minhas atividades no Hospital-Dia inteirandome da rotina e conhecendo os usuários e a equipe com a qual eu iria atuar. Era uma equipe interdisciplinar, o que já possibilita uma visão mais ampla da pessoa que necessita de atendimento, composta de 16 técnicos em saúde mental, sendo quatro psiquiatras (um coordenador do serviço), eu, como enfermeira, três técnicas de enfermagem sob minha supervisão, dois musicoterapeutas, duas psicólogas e quatro terapeutas ocupacionais (uma é vice-coordenadora do serviço). 0 corpo técnico-administrativo desse hospital está composto por uma recepcionista, uma técnica de informática, uma auxiliar de serviços gerais e uma auxiliar administrativa.

Todos os técnicos de nível superior têm função semelhante no convívio do serviço, guardada as especificidades de cada profissão. Como, por exemplo, a prescrição de medicação atribuição do médico, o atendimento psicoterápico - atribuição do psicólogo, a verificação de sinais vitais - atribuição da equipe de enfermagem, entre outras.

Possuímos um total de 144 usuários, com uma freqüência diária de cerca de 70 deles desenvolvendo atividades, do tipo grupo e oficina, de segunda a sextafeira, das 8:00h às 16:00h. Durante esse período, são oferecidos o café da manhã, a colação (lanche entre o desjejum e 0 almoço), o almoço e o lanche da tarde.

No início do tratamento, após a avaliação inicial de acolhimento do usuário, um técnico fica responsável por coletar informações sobre ele, que constarão em seu prontuário. Nessa entrevista com o usuário e/ou seu familiar, é feita uma identificação, uma síntese de sua trajetória de vida (antes e após seu adoecimento), seus contatos sociais, seus gostos e principalmente, a elaboração de um projeto terapêutico individual, no qual depois de apresentadas as atividades disponíveis no serviço, o usuário escolhe participar das que mais the agradam.

São oferecidas atividades programadas que possibilitam um tratamento intensivo incluindo a família nesse processo. A assistência é realizada por meio de diversos grupos terapêuticos que compõem um trabalho amplo e diferenciado que se constituem em: terapia ocupacional, reunião de familiares, atividades recreativas e grupos operativos, sempre visando tanto o desenvolvimento de habilidades sociais e pessoais, como bons hábitos de vida e saúde. Esse trabalho dá destaque ao lado mais saudável da vida do paciente trabalhando assim, a parte menos comprometida, como Villas Boas ${ }^{6}$ enfatiza.

Ainda de acordo com esse autor, cada atividade realizada representa para o usuário uma oportunidade de organização de pensamento, emoções e ações que se desenvolvem através de rotinas semanais. Nesses grupos em que as atividades são realizadas, é estimulada uma troca saudável e terapêutica entre os usuários que se beneficiam compreendendo que, a experiência do outro é semelhante a sua.

Procurei conhecer as atividades desenvolvidas e seus respectivos horários, bem como qual o técnico que a coordenava. Entre as atividades oferecidas podemos citar as seguintes oficinas terapêuticas: Antitabagismo, Qualidade de vida, Corpo e Som, Bijuteria, Cancioneiros, Assembléia de pacientes, Salão de Beleza, Informática, Grupo de Mulheres, Grupo de Homens, Brechó, Pintando e Bordando, Grupo de Medicação, Gerart, Culinária, Grupo de Acolhimento, Sala de Leitura, Grupo de Acompanhamento, Cine Pipoca, Bom Dia, Doce Aroma, Tapeçaria, entre outras.

\section{AS DIFICULDADES}

Uma das dificuldades que senti foi a de atuar em espaços de atendimento junto a uma equipe interdisciplinar, condição primordial para 0 atendimento de pessoas com sofrimento psíquico, haja vista que 0 curso de graduação não forma enfermeiros para este tipo de trabalho, de acordo com Mello ${ }^{7}$.

Em seu estudo, Tavares ${ }^{8}$ afirma ser possível pensar a prática criativa da Enfermagem Psiquiátrica transformando os modos e tecnologias do cuidar, na perspectiva da promoção do sujeito, apesar da complexidade do processo intersubjetivo. 
Pude perceber que, no trabalho em equipe, o relacionamento significa o encontro de diferentes histórias pessoais. Cada categoria profissional inserida da equipe interdisciplinar, atua em um espaço demarcado por um saber próprio, específico de sua formação acadêmica. Porém, elas se integram e se complementam buscando um consenso constante, com discussões freqüentes e avaliações sistemáticas de suas práticas objetivando uma melhor assistência e um melhor ambiente profissional. Essa articulação acontece uma vez por semana na "reunião clínica", na qual a presença de todos os técnicos é obrigatória. É nesse lugar, que toda a sugestão e idéia é apresentada discutida e decidida de acordo com a equipe, de maneira harmoniosa. Entretanto o desgaste, os atritos e as cisões são freqüentes e inevitáveis entre elementos de uma equipe interdisciplinar. Por esse motivo, as reuniões são de extrema importância para que as opiniões possam aproximar-se num exercício de flexibilidade.

Entretanto, nem sempre é possível levar um problema para a reunião de equipe devido à urgência de sua resolução. Para essas intercorrências que acontecem durante as rotinas, foi criado 0 "coordenador do turno" que então resolve e determina, após consultar o restante da equipe presente no momento.

Outro problema enfrentado por mim foi o de encontrar uma oficina que me despertasse interesse e me encantasse a ponto de desempenhá-la com tamanho estímulo me tornasse um contato terapêutico, algo que fizesse diferença para o usuário. Afinal eu nunca havia feito isso e não tinha muito tempo para me dedicar a esse tipo de atividade, em decorrência da dinâmica, muitas vezes conturbada dos plantões. Creio que não ensinam ao enfermeiro a desenvolver atividades de reabilitação. Ensinam até hoje ao enfermeiro, a cuidar de um cliente apenas, quando na prática ele assume 70 por dia que necessitam atividades reabilitadoras.

Após me interar e buscar informações sobre os objetivos e as funções desse tipo de atividade, passei a coordenar a Oficina de Leitura, onde lemos e falamos sobre textos relacionados com o momento vivido, e a Oficina de Mulheres onde o grupo, composto apenas de mulheres, elege e discute um tema em um ambiente descontraído e sem melindre.

Concordei em realizar também a Assembléia de Pacientes, uma vez por semana, e de terminar de compor o Salão de Beleza, uma oficina que, além do convívio, visa o estímulo ao autocuidado e o incentivo à auto-estima dos pacientes que freqüentam através de cuidados com a aparência. Esse salão já estava encaminhado faltando apenas alocar os móveis, espelhos, prateleiras, esmaltes, xampus, cremes etc. Após a inauguração do Salão, passei a coordenar esta oficina que atualmente é desenvolvida pela técnica de enfermagem que está de plantão.

Sob minha responsabilidade também está o Posto de Enfermagem e todas as funções que Ihe são inerentes como provisão e previsão de material, administração de medicação, verificação de sinais vitais, curativos e quaisquer outros procedimentos clínicos necessários. Não senti qualquer dificuldade com relação a essas atividades.

Um importante papel da equipe de saúde mental é a manutenção de um ambiente de liberdade e acolhimento, respeito às pessoas e às leis da comunidade, estímulo às habilidades e capacidades emergentes, através de estudos e reuniões freqüentes para se discutir a orientação referente a cada cliente (Rocha ${ }^{9}$ ).

\section{CONCLUSÃO}

Através da minha experiência, este relato pode demonstrar que, durante sua formação, o enfermeiro foi direcionado para desenvolver ações técnicas claras, previsíveis e definidas. Em Saúde Mental, o cuidado não se baseia em intervenções objetivas ou previsíveis, uma vez que a relação com o paciente é dinâmica e contínua.

Concordo com Souza ${ }^{10}$ quando afirma que, na assistência em enfermagem psiquiátrica e em saúde mental, é exigida do enfermeiro uma postura de iniciativa e criatividade, cujas oportunidades nem sempre lhes são oferecidas na graduação e na instituição.

Esta assistência exige do profissional iniciativa, criatividade e diferentes modos de assistir. Assim, 0 cuidar é constituído pelo enfermeiro no instante da interação visando gerar crescimento, autonomia e desenvolvimento de quem é cuidado, para possibilitar uma melhora da qualidade de vida desse sujeito através do vínculo afetivo e social, com a garantia do espaço da diferença e do acolhimento.

0 enfermeiro deverá ser preparado para atuar em novos modelos, com enfoque de serviços extrahospitalares e de reabilitação psicossocial. Do tradicional ao psicossocial, do tecnicista à satisfação das necessidades do usuário, assumindo novas tarefas como, por exemplo, maior envolvimento com familiares, adequando-se às mudanças advindas da atual política de saúde mental vigente no país. Para que isso ocorra, é necessário que os acadêmicos de enfermagem tenham a oportunidade de exercer a prática curricular também em serviços substitutivos, subsidiados pela postura do docente que busca um ensino crítico-reflexivo e direcionado para os ideais da Reforma Psiquiátrica. 


\section{Referências}

1. Jorge MAS. Engenho dentro de casa: sobre a construção de um serviço de atenção diária em saúde mental. [dissertação de mestrado] Rio de Janeiro (RJ): Ed da FIOCRUZ/ENSP; 1997.

2. Carvalho MC. Os desafios da desinstitucionalização. In: Figueiredo AC, Cavalcanti MT, organizadoras. A reforma psiquiátrica e os desafios da desinstitucionalização: contribuições à $2^{a}$ Conferência Nacional de Saúde Mental. Rio de Janeiro(RJ): IPUB/CUCA; 2001.

3. Loyola CM, Rocha RM. Apresentação. Cad IPUB 2000; 6(19): 710. Tema: Compreensão e crítica para uma clínica de enfermagem psiquiátrica.

4. Rodrigues ARF. Enfermagem psiquiátrica: saúde mental: prevenção e intervenção. São Paulo(SP): EPU;1996.

5. Monteiro CB. 0 paciente que manifesta agressividade na internação psiquiátrica: a representação do enfermeiro. Esc Anna Nery Rev Enferm 2004 dez, 8(3): 439-47

6. Vilas Boas MA. Passagem de plantão de enfermagem em um hospital-dia psiquiátrico. [dissertação de mestrado] Ribeirão Preto (SP): Escola de Enfermagem/ USP; 2004

7. Mello R. A questão da interdisciplinaridade no dia-a-dia da enfermeira que atua em centros de atenção diária de saúde mental. Rev Bras Enferm 1998 jan/mar; 51(1): 19-34.
8. Tavares CMM. Prática criativa da enfermagem psiquiátrica:fatores intervenientes no seu desenvolvimento. Esc Anna Nery Rev Enferm 2002,abr,6(1):107-17.

9. Rocha RM. Enfermagem em saúde mental. $2^{\mathrm{a} e d}$. Rio de Janeiro(RJ): Senac Nacional; 2005.

10. Souza MCB. M. Ações de enfermagem no cenário do cotidiano de uma instituição psiquiátrica. Rev Latino-Am Enfermagem. [online]. 2003 out ; [citado 12 março 2005]; 11(5): 678-684. Disponível em: http://www.scielo.br/scielo.php?script=sci_arttext\&pid=S010411692003000500017\&lng=pt\&nrm=iso.doi:10.1590/S010411692003000500017

\section{Sobre a Autora}

\section{Claudia Barbastefano Monteiro}

Mestre em Enfermagem - Escola de Enfermagem Alfredo Pinto/ UNIRIO. Professora Assistente da Universidade Gama Filho. Enfermeira do Instituto de Psiquiatria - IPUB/UFRJ. E-mail: Claudia.ipub@gmail.com 